\title{
Aspek Fisika dalam Perancangan Pesawat Aeromodeling Jenis Delta Wing
}

\author{
${ }^{1}$ Muhammad Zuhdi, ${ }^{2}$ Muh Makhrus, ${ }^{3}$ Wahyudi \\ ${ }^{1,2,3}$ Prodi Pendidikan Fisika, FKIP, Universitas Mataram, J1. Majapahit no.62, Mataram, \\ Lombok, Indonesia \\ Email Korespondensi: mzuhdi@unram.ac.id
}

\begin{tabular}{|c|c|}
\hline Article Info & Abstract \\
\hline $\begin{array}{l}\text { Article History } \\
\text { Received: } 15 \text { Mei } 2021 \\
\text { Revised: } 17 \text { June } 2021 \\
\text { Published: } 30 \text { June } 2021\end{array}$ & \multirow{2}{*}{$\begin{array}{l}\text { Physics Aspects in Designing Delta Wing Aeromodeling Aircraft. The Delta } \\
\text { Wing aeromodeling aircraft uses a symmetrical airfoil where the top of the } \\
\text { wing is the same as the bottom. The main aspects in the design of the Delta } \\
\text { Wing aircraft are center of gravity, the engine thrust, the air resistance, the lift } \\
\text { and the weight. Delta Wing aircraft are dominated by jet-engined aircraft with } \\
\text { the advantages of high speed and small air resistance. From the design and } \\
\text { field trials, it was concluded that the minimum thrust of the Delta Win aircraft } \\
\text { must be equal to } 2 \text { times the total weight of the aircraft so that the aircraft is } \\
\text { able to maneuver vertically, perform looping maneuvers, roll maneuvers and } \\
\text { hovering. }\end{array}$} \\
\hline $\begin{array}{l}\text { Keywords } \\
\text { thrust, delta wing, } \\
\text { aeromodeling }\end{array}$ & \\
\hline Informasi Artikel & Abstrak \\
\hline $\begin{array}{l}\text { Sejarah Artikel } \\
\text { Diterima: } 15 \text { Mei } 2021 \\
\text { Direvisi: } 17 \text { Juni } 2021 \\
\text { Dipublikasi: } 30 \text { Juni } 2021\end{array}$ & \multirow{2}{*}{$\begin{array}{l}\text { Pesawat aeromodeling jenis Delta Wing menggunakan airfoil berbentuk simetri } \\
\text { dimana bagian atas sayap pesawat sama dengan bagian bawahnya. Aspek } \\
\text { utama dalam perancangan pesawat Delta Wing adalah posisi titik berat } \\
\text { pesawat, gaya dorong mesin, gaya hambatan udara, gaya angkat pesawat dan } \\
\text { berat pesawat. Pesawat Delta Wing didominasi oleh pesawat bermesin jet } \\
\text { dengan keunggulan kecepatan yang tinggi dan hambatan udara yang kecil. Dari } \\
\text { perancangan dan uji coba di lapangan, disimpulkan bahwa gaya dorong } \\
\text { minimum dari pesawat Delta Win harus sebedar } 2 \text { kali berat total pesawat agar } \\
\text { pesawat mampu bermanuver secara vertikal, melakukan manuver looping, } \\
\text { manuver guling dan hovering.. }\end{array}$} \\
\hline $\begin{array}{l}\text { Kata kunci } \\
\text { gaya dorong, delta wing, } \\
\text { aeromodeling, }\end{array}$ & \\
\hline
\end{tabular}

Sitasi: Zuhdi, M., Makhrus, M., \& Wahyudi, W. (2021). Aspek Fisika dalam Perancangan Pesawat Aeromodeling Jenis Delta Wing. Kappa Journal, 5(1), 49-56.

\section{PENDAHULUAN}

Pesawat aeromodelling memiliki prinsip kerja yang sama persis dengan pesawat yang sesungguhnya. Faktor fisis yang sangat penting pada ada pesawat sesungguhnya maupun pesawat air modeling adalah gaya-gaya yang bekerja pada pesawat. Ada empat gaya utama yang bekerja pada pesawat, yang pertama adalah gaya dorong atau thrust, yang kedua adalah ah gaya hambatan udara atau drag force, yang ketiga adalah ah gaya angkat atau up lift dan yang keempat adalah berat pesawat atau all unit weight (auw). Penelitian ini ini bertujuan untuk mengetahui hubungan antara gaya dorong minimal pesawat Delta terhadap berat keseluruhan pesawat.

Gaya angkat pesawat dihasilkan oleh bentuk airfoil pada sayap yang memberi dampak pada kecepatan udara dibawah dan diatas sayap. Ada dua macam airfoil pada pesawat, yaitu airfoil asimetri dan airfoil simetri. Airfoil asimetri memiliki keunggulan yaitu gaya angkat yang besar tetapi dengan kelemahan gaya hambatan udara yang besar pula. Hambatan udara ini yang menyebabkan pesawat dengan airfoil asimetri memiliki kecepatan yang yang rendah dibandingkan dengan pesawat dengan airfoil simetri. Keunggulan airfoil simetri yaitu drag 
force atau gaya hambatan udara yang kecil, tetapi memiliki kelemahan yaitu gaya angkat yang kecil pula, sehingga airfoil simetri cocok jika digunakan untuk pesawat dengan beban ringan akan tetapi dengan kecepatan tinggi.

Pesawat Delta Wing adalah pesawat dengan sayap berbentuk delta. Keunggulan dari pesawat ini adalah kecepatannya yang tinggi dikarenakan hambatan udara yang kecil. Pesawat Delta Wing pada umumnya didominasi oleh pesawat bermesin jet dengan gaya dorong yang yang sangat besar.

Pesawat aeromodeling adalah pesawat berukuran kecil yang merupakan model dari pesawat sesungguhnya. Pada mulanya pesawat model ini digunakan dalam merancang dan ujicoba pesawat yang sesungguhnya. Uji coba pesawat model ini dijadikan acuan sebagai dasar dalam pembuatan pesawat dalam ukuran yang sebenarnya.

Pada perkembangannya, Aeromodelling dijadikan sebagai kegiatan dengan tujuan edukasi, rekreasi, olahraga maupun bisnis. Pada mulanya, kegiatan aeromodelling hanya diikuti oleh kalangan tertentu saja, karena peralatannya yang saat itu masih tergolong mahal. Pada saat ini kegiatan Aeromodelling dapat diikuti oleh berbagai lapisan masyarakat, dikarenakan perkembangan teknologi yang telah menjadikan berbagai komponen pesawat aeromodelling mudah dibuat dengan harga harga yang cukup murah.

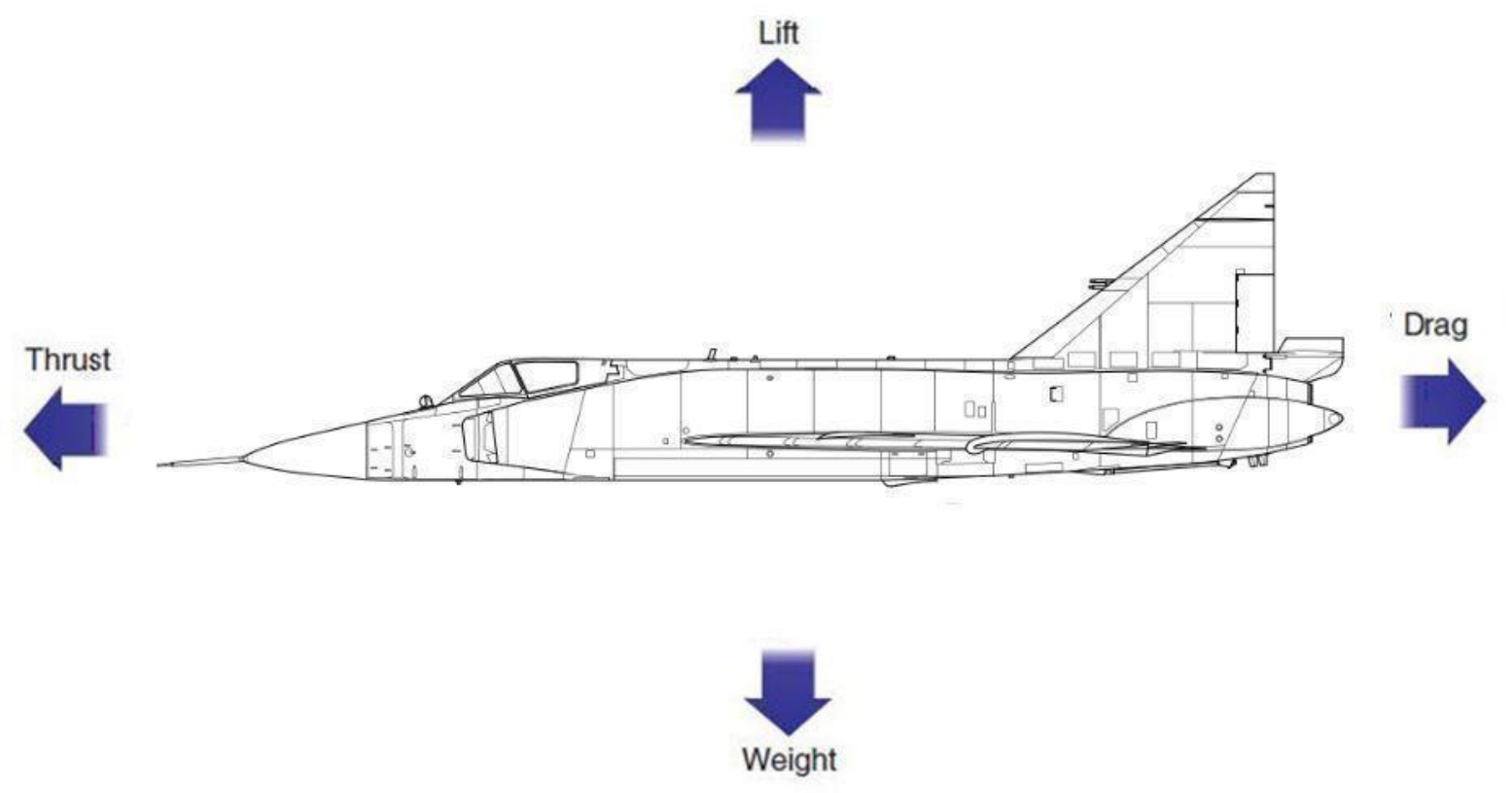

Gambar 1. Gaya dorong, gaya angkat, hambatan udara dan berat yang bekerja pada pesawat udara saat terbang.

Ada tiga macam pesawat aeromodelling yang biasa dibuat yaitu pesawat free flight, control line, dan remote control. Pesawat free flight diterbangkan tanpa menggunakan kontrol kontrol eksternal dari permukaan tanah. Gerakan pesawat free flight ini semata-mata hanya tergantung pada setting awalnya, serta kecepatan dan arah angin. Pesawat aeromodelling yang kedua adalah pesawat control line yang dikontrol dengan tali panjang, sehingga terbangnya pesawat selalu mengelilingi pilot yang mengendalikan dengan tali. Jenis pesawat aeromodelling yang ketiga adalah pesawat remote control yang dikontrol dengan dengan transmitter remote control yang berada di tangan pilot dan menggunakan penerima (reciever) yang diletakkan di dalam pesawat. Transmisi sinyal kendali pada remot control ini berbasis digital dan berada pada spektrum gelombang radio dengan frekwensi 2,4 GHz.

Pesawat aeromodeling dengan ukuran kecil, sedang dan menengah banyak digunakan oleh masyarakat untuk keperluan tertentu. Pesawat ini dalam bahasa Inggris disebut dengan UAV atau unmanned aerial vehicle, atau dalam Bahasa Indonesia sering disebut dengan 
PTTA atau pesawat terbang tanpa awak. Pada mulanya riset awal pesawat ini diperuntukkan untuk sitem pertahanan dan keamanan. Namun dalam perkembangannya penggunaan PTTA secara luas didominasi oleh pemanfaatan kamera untuk seni fotografi (footage) dan penggunaan kamera dan sensor lain untuk survei kebumian. Pemanfaatan lainnya yaitu sebagai sarana dan instrumen pembantu dalam produksi pertanian, misalnya penyemprotan pupuk atau penyemprot hama. Riset tentang aeromodelling telah banyak dilakukan oleh beberapa peneiti terdahulu. Hermanto, pada tahun 2018 membuat alat untuk mengukur gaya tarik motor brushless, hasil analisis risetnya menunjukkan bahawa gaya tarik tergantung pada jenis motor listrik dan jenis baling-baling (propeller) yang digunakan. Putra dkk. tahun 2019 membuat media interaktif dalam rangka pengenalan kegiatan aeromodelling. Anggriawan 2014 melakukan penelitian aeromodelling untuk mendeskripkan relevansi dari materi ekstrakurikuler Aeromodelling terhadap standar yang ditetapkan, dengan metode diskriptif. Nugraha dan Kushartanti 2018, melakukan penelitian efektivitas suatu pelatihan aeromodelling. Rokhmana, pada tahun 2013 melakukan pemetaan dengan penggunakan PTTA. Rokhmana, pada tahun 2013 meneliti tentang percepatan pemetaan kadaster memanfaatkan teknologi wahana udara tanpa awak. Suryasaputra dkk., pada tahun 2014 menggunakan PTTA untuk keperluan fotografi udara dengan Aeromodelling And Payload Telemetry Research Group (APTRG). Miraza dan Isranuri, pada tahun 2012, menganalisa tegangan pada sayap pesawat aeromodeling. Majid dkk., pada tahun 2015 melakukan identifikasi model dari pesawat udara tanpa awak sayap tetap jenis Bixler.

Penelitian ini ini bertujuan untuk mengetahui hubungan antara gaya dorong minimal pesawat delta terhadap berat keseluruhan pesawat, agar pesawat delta dapat melakukan manuver dasar yaitu looping, manuver guling, dan manuver vertikal.

\section{METODE}

Penelitian ini dilakukan dengan beberapa tahap yaitu perancangan dan pembuatan pesawat delta wing, penentuan titik berat (CG), pengukuran berat terbang pesawat, pengukuran gaya dorong pesawat, uji coba terbang awal, dan uji coba manuver dasar. Pesawat ini ini dirancang oleh penulis tanpa menggunakan plan dari pesawat yang sudah ada, artinya pesawat ini ini belum pernah dibuat sebelumnya dengan skala yang sama. Panjang keseluruhan pesawat dari nose hingga tail adalah $68,5 \mathrm{~cm}$, sedangkan lebar sayap atau wingspan adalah $79 \mathrm{~cm}$. 


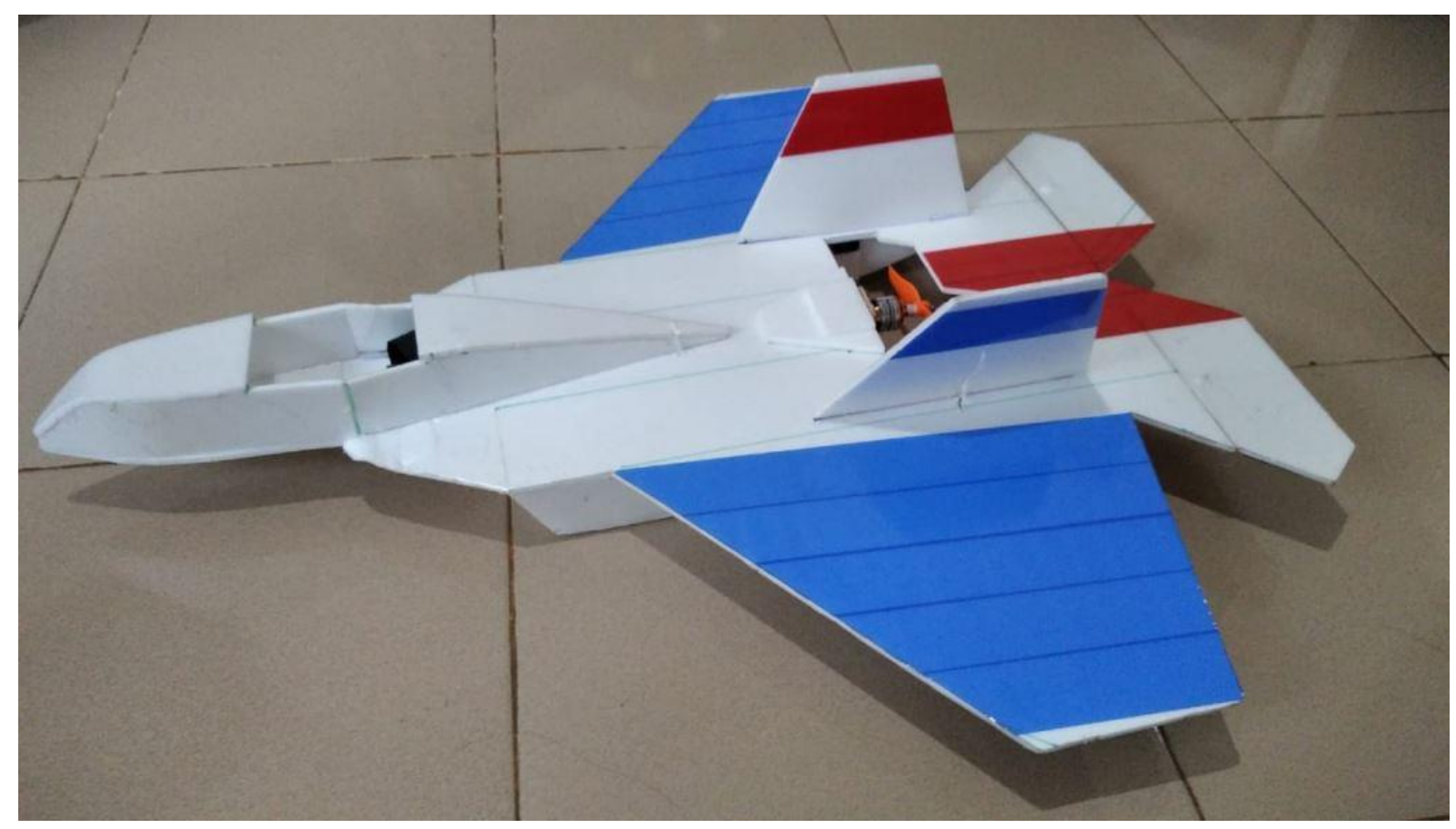

Gambar 2. Pesawat aeromodelling jenis delta wing yang telah diujicoba.

Pesawat aeromodelling jenis delta wing yang telah dibuat dan diujicoba pada penelitian ini ditunjukkan oleh gambar 2. Berat terbang (all unit weight) pesawat ini sebesar 426 gram force yang setara dengan 4,2 Newton menggunakan asumsi percepatan gravitasi seesar $9,8 \mathrm{~m} / \mathrm{s}^{2}$. Pengukuran berat terbang dilakukan dengan menimbang berat pesawat secara keseluruhan yang terdiri dari polyfoam, motor brushless, electronic speed controller (ESC), transmitter, servo, pushrod dan baterai. Pengukuran gaya dorong pesawat dilakukan dengan menggunakan timbangan digital sebagaimana ditunjukkan pada gambar 2. Gaya dorong yang diukur terdiri dari 5 kali pengukuran dengan kapasitas throttle yang berbeda-beda yaitu 20\%, $40 \%, 60 \% 80 \%$, dan $100 \%$. Walaupun remote flysky I-6 memungkinkan untuk menghasilkan throttle sebesar $120 \%$, tetapi hal ini tidak dilakukan untuk menghindari penurunan tegangan akibat over discharge yang akan mengakibatkan cut off sehingga mesin mati seketika.

Vertical stabilizer terdiri dari 2 buah dengan sudut kemiringan 60 derajat terhadap sayap pesawat. Kemudi pesawat dilakukan dengan menggerakkan bagian ekor pesawat tanpa menggunakan aileron maupun rudder pada vertical stabilizer. Motor pendorong berada ada di tengah antara 2 vertical stabilizer.

Baterai yang digunakan adalah lithium Polymer 3S (11,1 Volt) dengan kapasitas 2200 mili Ampere hour. ESC yang digunakan memiliki suplai arus hingga 40 Ampere. Servo sebagai penggerak stabilizer yang digunakan adalah tipe $9 \mathrm{G}$, sedangkan motor penggerak utama menggunakan merek Turnigy dengan serial D2826/6 dengan konstanta putaran 2200 KV. Remote control yang digunakan adalah merek Flysky I-6. 


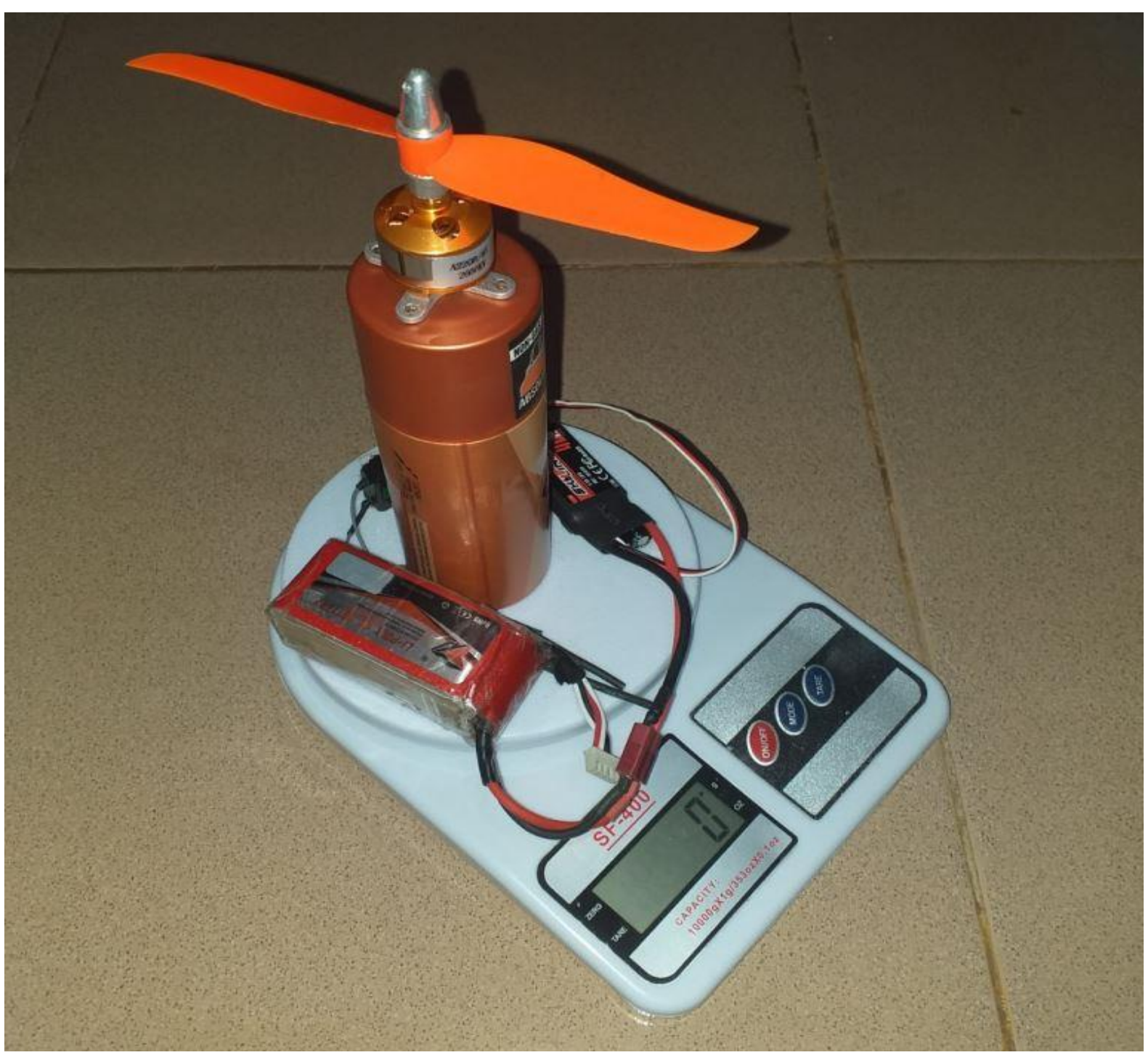

Gambar 3. Pengukuran gaya dorong motor brushless dengan timbangan digital SF-400.

Pengukuran gaya dorong motor listrik dilakukan dengan timbangan digital seri SF400 dengan kapasitas maksimum $10 \mathrm{~kg}$ sebagaimana ditunjukkan oleh gambar 3. Dalam melakukan penimbangan perlu diperhatikan bahwa semua unit harus menempel pada timbangan dengan baik sehingga baterai, receiver, dudukan motor harus dilem sementara pada dudukan timbangan agar ketika terjadi dorongan posisinya tidak berubah sehingga tidak mempengaruhi gaya dorong yang terukur. Kabel juga tidak boleh menyentuh bagian luar timbangan agar tidak mengurangi gaya dorong terukur. Motor brushless sengaja diletakkan pada ketinggian yang cukup agar dapat mengambil udara dengan ruang yang cukup sehingga mirip dengan kondisi terbang, sehingga gaya dorong terukur lebih akurat. Keunggulan timbangan digital seri SF-400 adalah ketika dinyalakan dalam keadaan terdapat beban, maka semua beban terkoreksi, sehingga angka menunjukkan pembacaan nol, sehingga dorongan yang terukur saat dilakukan pembebanan adalah beban tambahan setelah instrumen timbangan dinyalakan.

\section{HASIL DAN PEMBAHASAN}

Pengukuran berat pesawat ini dilakukan menggunakan timbangan digital tipe SF-400 dengan hasil pengukuran 426 gram. Pengukuran gaya dorong motor brushless juga dilakukan dengan timbangan digital yang sama. Hasil pengukuran dengan posisi throttle berbeda-beda 
menghasilkan gaya dorong sebagaimana ditunjukkan oleh tabel 1. Hasil pengukuran pada tabel 1 menunjukkan bahwa gaya dorong hampir linier terhadap prosentase posisi throttle. Sedikit perbedaan yang terjadi semata-mata karena ketelitian penggerakan throttle pada remote control.

Tabel 1. Gaya dorong yang dihasilkan oleh posisi throttle

\begin{tabular}{ll}
\hline Throttle $(\%)$ & Gaya Dorong $(\mathrm{N})$ \\
\hline 20 & 1,98 \\
40 & 4,02 \\
60 & 6,32 \\
80 & 9,45 \\
100 & 12,3 \\
\hline
\end{tabular}

Tabel 1 menunjukkan besar gaya dorong yang dihasilkan oleh throttle dengan persentase yang berbeda-beda. Brushless motor D2826/6 memiliki diameter $28 \mathrm{~mm}$ dan tebal motor $26 \mathrm{~mm}$ dengan konstanta putaran $2200 \mathrm{KV}$ yang artinya tiap kenaikan tegangan 1 volt menghasilkan pertambahan kecepatan putaran 2200 RPM. Baling-baling (propeller) yang digunakan menggunakan jenis 2 bilah dengan diameter 6 inci. Dari tabel 1 tampak bahwa besarnya gaya dorong yang dihasilkan oleh motor sebanding dengan besar throttle yang diberikan.

Uji coba pertama pesawat ini dilakukan di bandara Selaparang, Rembiga Mataram. Tujuan dari ujicoba ini adalah untuk mengetahui ketepatan posisi centre of gravity (CG) yang menentukan stabilitas terbang pesawat. Penentuan awal letak CG dilakukan dengan mendorong pesawat dengan tangan hingga terbang secara horizontal. Jika pada uji ini sikap pesawat cenderung menukik (nose down), berarti letak CG terlalu ke depan sehingga harus ditambahkan beban di bagian belakang pesawat. Jika pada uji ini sikap pesawat cenderung mendongak (nose up), berarti letak CG terlalu ke belakang, sehingga harus ditambahkan beban di bagian depan pesawat. Video uji coba pesawat ini dapat dilihat di channel YouTube dengan link: https://www.youtube.com/watch?v=8IDYojSmSJU

Uji coba manuver dilakukan di lapangan Jempong Baru, sebelah barat laut Tugu Mutiara, kecamatan Sekarbela. Berbagai uji coba yang dilakukan untuk berbagai manuver ditunjukkan oleh tabel 2.

Tabel 2. Kemampuan manuver didasarkan pada posisi throttle pada remote control

\begin{tabular}{ccccc}
\hline Throttle & $\begin{array}{c}\text { Terbang } \\
\text { Lurus }\end{array}$ & $\begin{array}{c}\text { Manuver } \\
\text { Looping }\end{array}$ & $\begin{array}{c}\text { Manuver } \\
\text { guling }\end{array}$ & $\begin{array}{c}\text { Manuver } \\
\text { vertikal }\end{array}$ \\
\hline $20 \%$ & $\sqrt{ }$ & $\mathrm{X}$ & $\mathrm{X}$ & $\mathrm{X}$ \\
$40 \%$ & $\sqrt{ }$ & $\mathrm{X}$ & $\sqrt{ }$ & $\mathrm{X}$ \\
$60 \%$ & $\sqrt{ }$ & $\sqrt{ }$ & $\sqrt{ }$ & $\mathrm{X}$ \\
$80 \%$ & $\sqrt{ }$ & $\sqrt{ }$ & $\sqrt{ }$ & $\sqrt{ }$ \\
$100 \%$ & $\sqrt{ }$ & $\sqrt{ }$ & $\sqrt{ }$ & $\sqrt{ }$ \\
\hline
\end{tabular}

Tabel 2 menunjukkan bahwa manuver yang membutuhkan gaya dorong paling tinggi adalah terbang vertikal ke atas. Pada kolom pertama dengan posisi throttle $20 \%$ pesawat dapat terbang dengan mengandalkan gaya dorong yang kecil.

Manuver looping dapat dilakukan dengan dorongan minimal dari throttle sebesar $60 \%$. Manuver guling dapat dilakukan dengan dorongan minimal sebesar $40 \%$, akan tetapi pada kondisi ini ketika posisi pesawat terbalik (reversed) terdapat kecenderungan penurunan ketinggian yang signifikan, dimana hal ini tidak terjadi ketika posisi throttle $80 \%$ dan $100 \%$. Pada posisi throttle $80 \%$, semua manuver dapat dilakukan pada gaya dorong ini. Posisi 
throttle $80 \%$ memberikan gaya dorong sebesar 9,45 $\mathrm{N}$ yang besarnya dua kali berat terbang pesawat.

\section{KESIMPULAN}

Pesawat delta wing yang telah dibuat mampu melakukan berbagai manuver dasar. Hasil pengukuran berat pesawat adalah 426 gram force yang setara dengan 4,2 Newton. Hasil pengukuran gaya dorong mesin maksimal menunjukkan hasil 12,3 Newton pada posisi throttle $100 \%$. Hasil uji pesawat menunjukkan bahwa gaya dorong minimum untuk melakukan semua manuver dasar adalah 2 kali berat terbang pesawat.

\section{SARAN}

Untuk mendapatkan gaya dorong yang lebih besar, perlu dilakukan uji coba menggunakan brushless motor dengan ukuran 2832, $2700 \mathrm{KV}$ dengan propeller 3 bilah berdiameter 6 inci. Untuk pengukuran prosentase throttle yang lebih teliti sebaiknya digunakan remote control yang memiliki nilai luaran throttle saat di operasikan, misalnya remote dengan merek Spektrum atau Taranis.

\section{UCAPAN TERIMA KASIH}

Terimakasih kasih yang sebesar;besarnya kepada Agung Kuntowicaksono sebagai ketua Club Aeromodelling Lombok (CAL), Yoyok Rangga Askarani sebagai ketua Rinjani Aeromodelling Club (RAC), Lalu Dwik dan Danlanud Rembiga atas bantuan dalam perancangan, kamera shooting dan pengambilan data di Lapangan udara Rembiga.

\section{DAFTAR PUSTAKA}

Anggriawan, R., Karo-Karo, U., Suhayat, D., Relevansi Materi Ekstrakurikuler Aeromodelling Terhadap Standar Materi Mata Pelajaran MDTPU. Journal of Mechanical Engineering Education, Vol.1, No.1, Juni 2014.

Bekker, J. G., Craig, I. K., \& Pistorius, P. C. (1999). Modeling and Simulation of Arc Furnace Process. ISIJ International, 39(1), 23-32.

Hermanto, D, Perancangan Pengukur Kekuatan Motor Brushless Berbasis ESP8266, Jurnal Teknik Informatika dan Sistem Informasi ISSN 2407-4322, Vol. 5, No. 1, September 2018, Hal. 36-44 E-ISSN 2503-2933 36

Majid, A., Sumiharto, R., Wibisono, S.B., Identifikasi Model dari Pesawat Udara Tanpa Awak Sayap Tetap Jenis Bixler, IJEIS, Vol.5, No.1, April 2015, pp. 43 54.

Miraza, R.S., Isranuri, I., Analisis Tegangan Pada Sayap Horizontal Bagian Ekor Aeromodelling Tipe Glider Akibat Laju Aliran Udara Dengan Menggunakan Software Berbasis Computional Fluid Dynamic (CFD), Jurnal e-Dinamis, Volume I, No.1 Juni 2012.

Nugraha, L.O., Kushartanti, W., Evaluation of Aeromodelling Coaching System, Advances in Social Science, Education and Humanities Research, volume 278, 2nd Yogyakarta International Seminar on Health, Physical Education, and Sport Science (YISHPESS) 2018.

Putra, I.P.C.A., Rusli, M., Suniantara, I.K.P., Aplikasi Multimedia Interaktif Pengenalan Olahraga Aeromodelling, Seminar Nasional Sistem Informasi dan Teknik Informatika Sensitif 2019.

Rokhmana, C.A., Percepatan Pemetaan Kadaster Memanfaatkan Teknologi Wahana Udara Tanpa Awak ,Bhumi No. 38 Tahun 12, Oktober 2013. 
Setyasaputra, N., Septian, F., Fernanda, R., Bahri, S., Rahmatio, I.D., Dirgantoro, B., Platform Unmanned Aerial Vehicle Untuk Aerial Photography Aeromodelling And Payload Telemetry Research Group (APTRG), Seminar Nasional Penginderaan Jauh 2014. 